Article

\title{
Wholistic and Ethical: Social Inclusion with Indigenous Peoples
}

\author{
Kathleen E. Absolon \\ Faculty of Social Work, Wilfrid Laurier University, Waterloo, ON N2L 3C5, Canada; E-Mail: kabsolon@wlu.ca
}

Submitted: 30 October 2015 | Accepted: 22 January 2016 | Published: 23 February 2016

\begin{abstract}
This paper begins with a poem and is inclusive of my voice as Anishinaabekwe (Ojibway woman) and is authored from my spirit, heart, mind and body. The idea of social inclusion and Indigenous peoples leave more to the imagination and vision than what is the reality and actuality in Canada. This article begins with my location followed with skepticism and hope. Skepticism deals with the exclusion of Indigenous peoples since colonial contact and the subsequent challenges and impacts. Hope begins to affirm the possibilities, strengths and Indigenous knowledge that guides wholistic cultural frameworks and ethics of social inclusion. A wholistic cultural framework is presented; guided by seven sacred teachings and from each element thoughts for consideration are guided by Indigenous values and principles. From each element this paper presents a wholistic and ethical perspective in approaching social inclusion and Indigenous peoples.
\end{abstract}

\section{Keywords}

Anishinaabe; colonization; ethical; exclusion; inclusion; Indigenous; Indigenous knowledge; oppression; racism; reconciliation; restoration; resurgence; wholistic

\section{Issue}

This article is part of the issue "Social Inclusion and Indigenous Peoples", edited by Pat Dudgeon (University of Western Australia, Australia), Waikaremoana Waitoki (University of Waikato, New Zealand), Rose LeMay (Wharerātā Group, Canada) and Linda Waimarie Nikora (University of Waikato, New Zealand).

(C) 2016 by the author; licensee Cogitatio (Lisbon, Portugal). This article is licensed under a Creative Commons Attribution 4.0 International License (CC BY).

\section{Introduction}

Crunch crunch crunch crunch.

Whispy biting wind swipes my checks like sandpaper and salt.

It tingles in a refreshing way. I like it-but not too much. Crunchy crispy snow sends vibrations of my walk across creation.

There is no hiding or sneaking up on anything in this crispy cold snow.

I like that sound. It's alive and I am here. I am included. I stop, breath and take in what I am often too busy to see and experience.

Looking, feeling, listening and sensing. Thoughts go quiet. Attention to sounds and sights.

It's often the little things that we exclude, that we don't look at or feel.

Vast blueness covers the sky and it's chillingly

deceiving-it looks summery.

Blue skies and cold airs flow in an invisible icy veil.
The wind bites my face and the snow would turn my toes black if exposed.

Rays of sunshine line my face and send warmth that allows forgiveness of the biting cold.

Beautifully powerful and powerfully deadly.

Dualities exist all around us.

Spirit is here. I feel Creation. I know I am part of Creator's web.

Creation will teach and guide for life's inclusion - we must listen.

When I was invited to submit an article for this special edition I initially thought maybe they invited the wrong person. Who me? I realized this initial response is an impact of being excluded and feeling alienated throughout my life. With caution I proceeded and accepted the invitation. Now what? Inclusion begins with voice in Creation experiencing and being. I know I belong. Inclusion simply begins with an invitation. Come on in! I acknowledge the journal for making the invita- 
tion. In this article, I include my whole self and locate who I am. I use whole with a " $w$ " to denote wholeness as in complete, circular and full. Canada is my context. The settler colonial history directly impacts my experiences and the place from which I write.

I am an Anishinaabekwe (Ojibwe woman). My Anishinaabe name is Minogiizhigokwe which means Shining Day Woman. I am a member of Flying Post First Nation which is in Northern Ontario, Canada. In Canada, Indigenous territories have been eroded to "lands reserved for Indians" under the assimilative Federal legislation of the Indian Act $1876 .{ }^{1}$ I have never lived on my reserve lands; exclusion not inclusion is the reason; Indian Act legislation outlawed and excluded us from ourselves at every level of our existence. When my Ojibwe mother married my British father and under the patriarchal and sexist Indian Act legislation, her Treaty rights and Indian Status were revoked. In 1985, the Indian Act was amended with Bill C 31 as a result of Indigenous women's activism. She then had her Indian status reinstated along with all her offspring. Aggressive policies of assimilation were Federally legislated in Canada and from the ages of 5 to 15 my mother was sent to the Chapleau Indian Residential School in Northern Ontario. Despite the assimilators efforts to eradicate our culture, we were raised close to the land and my family kept us closely connected to Creation. My blend includes many layers comprised of my connection to the land, cultural identity, impacts of colonial socialization and internalization, decolonizing and Indigenizing while reclaiming, relearning and recovering my whole self. My voice, spirit, heart, mind and body guide my writing. How I locate in my writing will shift and change as I shift and grow.

Within this paper, I include as a key reference my Ojibwe/Anishinaabe teaching and learning as Indigenous researcher, educator, knowledge carrier and community helper. I also acknowledge the duality of exclusion and inclusion in the Indigenous and Canadian peoples' contexts. It may not speak to readers who require Eurowestern literature to substantiate Indigenous knowledge. My approach contributes to the collective by including my Indigenous lens. Change is imperative. I participate in change by challenging the dominance of Eurowestern theories and beliefs and put forth a wholistic perspective rooted in Anishinaabe teachings relative to social inclusion and Indigenous peoples. These teachings come from oral narratives, teachings and written work. Practices rooted in local contexts and traditions inform this paper and I strive to incorporate and recover my Indigenous traditions into thought and models of social inclusion in an authentic manner whereby, "the local culture is used as a prima-

\footnotetext{
1 To learn more about the Indian Act, University of British Columbia has a critically informed website: http://indigenousfoundations.arts.ubc.ca/home/governmentpolicy/the-indian-act.html
}

ry source for knowledge and practice development" (Gray, Coates, \& Yellow Bird, 2008, p. 5). Rooted in my Anishinaabe tradition my writing has goals of generating space for re-storing Indigenous knowledge and perspectives. As Dumbrill and Green (2008) note, this assertion is necessary and needed for the disruption of ongoing dominance of Eurowestern worldviews. My challenge is to recognize that values and ideas of inclusion from and within a colonized environment still contain western values that I have internalized. I need to use Anishinaabe wholistic frameworks to keep me in check and to ensure my perspective is inclusive and whole. Authors Mel Gray, John Coates and Michael Yellow Bird (2008) believe that "good and effective social work practice demands that we make culture explicit in thinking and practice. This [was] a substantial conclusion that emerged in our workshops, which brought together scholars from around the world to discuss the most significant global trends related to Indigenous and cross cultural social work" (p. 6). My challenge is to present an Anishinaabe wholistic worldview that is inclusive, yet not pan-Indian, that also presents a universal circular philosophy, yet recognizes our unique locations. It's not easy. However, I too believe that practice that is driven by cultural values is relevant and good practice. I proceed knowing that I will make mistakes inclusively.

An Ojibwe worldview is a wholistic circular worldview inclusive of all directions and could be described to be a 360 degree lens (Dumont, 1976). The resurgence of Indigenous pedagogies and knowledge are relevant in making contributions to insightful models toward change (Cajete, 1994; Simpson, 2011). Today, many Indigenous authors are promoting this stance where "Nishnaabeg thinkers believe we are in the period of the Seventh Fire. It is the responsibility of the new people, the Oshkimaadiziig, to pick up the pieces of our lifeways, collectivize them and build a political and cultural renaissance and resurgence" (Simpson, 2011, p. 66). Citing pioneering authors' work demonstrates this journey. The journey continues toward asserting our existence and being included.

This article is presented and organized firstly with a gaze of skepticism by illuminating the challenge of social inclusion in the contexts where exclusion dominates. Following this awakening is a glance into the spaces where hope resides and change is resident. Wholistic and ethical change is then presented within a medicine wheel circle to facilitate inclusivity and balance where each direction of spirit, heart/relationship, mind/knowledge and physical/presence are explored. Historically, concepts of the Medicine Wheel were derived from central North America and contribute in the resurgence of wholistic Indigenous approaches (Linklater, 2014). Following, each direction are guiding questions to reflect upon and perhaps act upon. Finally, each direction of the whole is guided by principles of humility, love, truth, honesty, respect, wisdom and 
bravery: the seven sacred teachings (Simpson, 2011). These principles ground each direction in terms of values and ethics of practice. Concluding thoughts bring closure to this article. I skeptically begin.

\section{Skepticism and Hope: The Duality in Ex/Inclusion}

My skepticism emerges in a critical gaze at how colonialism in Canadian policy and practice has aggressively been driven to exclude, erode, erase and oppress Indigenous peoples in our homeland. Imperialism, colonialism, racism and oppression are all culprits eventually leading to the Canadian Federal Government instituting policies of aggressive assimilation such as Church run Indian Residential Schools (Dickason \& Newbigging, 2015; Graveline, 2010). These policies severely impacted my family and community; they systematically dismembered many of our families from one another at spiritual, emotional, mental and physical levels. Socially driven legislation and policies have been created to 'rid the Indian from the child' through the Indian Act, Residential School Act, Child Welfare, land dispossessions and so much more (Dickason \& Newbigging, 2015). All efforts were made to sever Indigenous peoples connection from our life source, our Mother Earth to pursue capitalism and global market power. Since contact on North America, invading colonizers have attacked Indigenous sovereignty, land rights and title in pursuit of the land and her natural resources to accumulate wealth and power. While there were many dehumanizing and very unsocial exclusionary mechanisms in colonial agendas for domination, they are not the focus of this paper. With that being said, recognizing that the intent of all subsequent and consequent institutional and structural acts and actions of social exclusion has been to actualize the colonizer's power and control over Indigenous peoples in order to have a reigning hand on the land and her resources. There are many layers and mechanisms of exclusion of Indigenous peoples in Canada. Consequently, as in many other colonized countries, Indigenous peoples' inclusion is often superficial and token.

Will is a key factor. Is there political will to begin becoming socially inclusive? For example, when commissions or inquiries are undertaken, such as the Royal Commission on Aboriginal Peoples ${ }^{2}$ from 1992 to 1996, the Manitoba Justice Inquiry, ${ }^{3}$ and the more recent Truth and Reconciliation Commission (TRC) ${ }^{4}$ from 2000 to 2015, comprehensive recommendations solidly based in individual, community testimonies and ethical research are made in final reports. These recommendations need to be taken seriously by Governments by

\footnotetext{
${ }^{2}$ See http://www.aadnc-aandc.gc.ca/eng/1307458586498/ 1307458751962

${ }^{3}$ See www.ajic.mb.ca/volume.html

${ }^{4}$ See www.trc.ca
}

placing them on strategic agendas and action plans with accompanying resources. In my experience, at many municipal and community levels, Indigenous people are not consulted and if it is a 'consultation,' it is constructed to seem like one, but is not authentically driven. Social inclusion in social policy, welfare, child welfare, social services and health is yet to be actualized. Indigenous people continue to represent the highest social statistics, yet are not included in solution finding and funding to remedy high mortality rates, homicide rates, suicide rates (an ultimate manifestation of exclusion), incarceration, violence, abuse, addictions, homelessness and poverty. This goes without saying, but it seems we need to keep saying that Indigenous peoples need to be included in discussions and decision-making processes to create solutions that are relevant and meaningful.

Indigenous peoples are leading the roads to change within our own communities which are as diverse as communities can be. With that being said, the road to social inclusion is clogged with political and social control agents, social ignorance, lack of political will, institutional racism, colonized structures and internalized colonialism and oppression. The idea of social inclusion and Indigenous people leaves more to the imagination and vision than current reality and actuality in Canada.

The whole picture is further complicated by the internalized contexts of Indigenous peoples. Indigenous peoples have many layers of internalized colonialism, racism and oppression to unravel while decolonizing, healing and restoring. Understanding the layers of historicity, impacts of genocide, colonization and subsequent intergenerational unresolved traumas that continue to plague and wreak havoc is foundational to having constructive conversations to redress exclusion in social movements. Inclusion in problem identification, problem solutions, and in all areas of restoration and reconciliation is necessary.

Are we ready? Ready for what? We don't know what we don't know. Susan Dion, a leading LenapePotawatami educator and scholar, accurately describes amnesia as a powerful tool breeding ignorance and inaction. Key variables and obstacles that impact any capacity to address social inclusion are ignorance, cultural and colonial amnesia, power, privilege and greed (Dion, 2009). Ignorance is a result of a society that doesn't know what it doesn't know until exposed to information, knowledge and experiences. Cultural and colonial amnesia is endemic and a lack of accurate knowledge in education creates a society that forgets, avoids, denies and negates the connections between personal and political, present, past and future. Through a gross omission, education is one of the main culprits in propagating social ignorance and colonial amnesia about Indigenous peoples and colonization in Canada. Let's not negate or ignore the underlying culprits and government's role in creating and maintaining colonial illit- 
eracy and inaction, ultimately leaving social injustice and inequity under the social radar and without social accountability by society. The connection becomes clearer in identifying who benefits when Canadians at large are socialized into a norm of ignorance and amnesia.

In Canada, ignorance prevails about the history and ongoing colonizing tactics against Indigenous peoples, thereby fuelling ignorance and amnesia at gross levels. People don't know what they don't know. Though this is changing with a new Federal leadership and recent media coverage of the Truth and Reconciliation book launch and a national inquiry into Murdered and Missing Aboriginal women, there is much work to do. Amidst this, Indigenous peoples want to grow and thrive as Indigenous peoples, not colonized Indigenous peoples. Many people unknowingly participate in colonial mechanisms because they just don't know or understand how to step into becoming a part of positive change so they either defer to Indigenous peoples (pass the buck) or freeze (and do nothing). I believe Indigenous peoples' history in Canada must be included to inform and address the illiteracy and ignorance. Undoubtedly, power is a major player in the operation of exclusion and power is never easily or voluntarily relinquished (Pinderhuges, 1998). The roots of exclusion must continue to be unveiled with a goal to depersonalize blaming the victims of a culture that perpetuates amnesia. Critical North American Indigenous scholars such as Howard Adams, Harold Cardinal, Sheila Cote-Meek, Vine Deloria Jr., Lauri Gilchrist, Eber Hampton, Emma LaRoque, Patricia Monture-Angus, Raven Sinclair, Fyre Jean Graveline (to name a few) and many others have published to restore accurate accounts and impacts of colonization for this very reason. Paulo Freire (1996) from Central America was an educator and alley who wrote about educating for change by teaching oppressed people to read and develop a critical consciousness about their conditions. The principles of critical education resonate within the Canadian context where people have been kept ignorant about oppression and colonization. As a critical Indigenous educator, I have witnessed that when learners grow in their political and social consciousness through knowledge based on the accurate and truthful accounts of colonization, they are in fact decolonizing, critically reflecting and connecting this knowledge to themselves and ultimately their social consciousness. Authentic action follows. Education ought to be created to foster socially conscience people and truth telling that emancipates peoples' minds, hearts, bodies and spirits is a part of that. Canada is a society that is in a treaty relationship with Indigenous peoples, the original Nations of this land (Dickason \& Newbigging, 2015). Only when the Canadian populous understand their treaty obligations in this relationship can we begin to understand the principle of inclusion.

Despite the skeptical picture, I confess my spirit carries hope and faith that we must never surrender or give up on taking our place in society and Creation. Decolonizing has begun and while Indigenous knowledge systems contain ethics, values and principles from which to build inclusion, we are continually confronted with the impacts of colonial trauma and must continue to do our work to restore ourselves individually and collectively. We must problematize archaic notions of paternalism and recognize the necessity of including those impacted by legislation, policies, practices and services in the development, planning and delivery at all phases and stages. This article crafts a culturally based framework and lens from which inclusion can be considered, operationalized and authentically acted upon.

\section{Hope: Culturally-Based Frameworks for Inclusion}

Indigenous peoples' resistance and resilience have always been strong and our spirit of survival even stronger because we know we belong, we stand up for Creation-she is our life source. Through my daughters Amanda and Healy, I have heard a slogan for inclusion, 'nothing about us without us' and while it has its roots in the Apartheid and HIV movements, it seems marginalized communities who are fighting for inclusion have adopted it. This term also resonates and echoes with what we in the Indigenous community are saying. 'Nothing about us without us' is clear in meaning and intent toward inclusion. Agendas that are rooted in equality, social justice and respect for diversity will create fertile ground for social inclusion in addressing matters of spiritual, emotional, mental and social wellness at individual, community, national and allied levels.

Leroy Little Bear $(2000,2012)$, a Blackfoot scholar, along with Vine Deloria Jr. (1973) and many other leading Indigenous knowledge keepers have lead the arduous journey of asserting Aboriginal knowledge, philosophy and foundations in guiding policy, education, research, science, law and justice. Little Bear (2000) affirms the cyclical, wholistic and paying attention to process in the whole:

"The idea of all things being in constant motion or flux leads to a holistic and cyclical view of the world. If everything is constantly moving and changing, the cosmic cycles are in constant motion, but they have regular patterns that result in recurrences such as the seasons of the year, the migration of the animals, renewal ceremonies, songs, and stories. Constant motion, as manifested in cyclical or repetitive patterns, emphasizes process as opposed to product." (p. 79)

Wholistic frameworks are important lenses to ensure and ground inclusivity in engagements with Indigenous peoples (Twigg \& Hengen, 2009). Indigenous worldviews and philosophies are guided by natural cycles and natural law with cyclical and circular frameworks repre- 
senting the layers and interconnections of relationships within Creation and life (Little Bear, 2000, 2012). Indigenous peoples are the knowledge keepers of this land and within our knowledge are cultural frameworks and teachings (Graveline, 1998; Verniest, 2006; Nabigon \& Wenger-Nabigon, 2012). Indigenous Elders tell us our original teachers are in Creation and it is important to observe and regard the natural world for guidance in contemplating issues and approaches wholistically. In this article, I am integrating a Medicine Wheel framework and Seven Sacred Teachings to help write about wholistic and ethical social inclusion. Other Indigenous scholars, like myself, have derived meaning and guidance from the natural world and Creation to inform how we contemplate and present wholistic approaches (Aboriginal Field of Study, 2015; Absolon, 2010, 2011; Cote-Meek, Dokis-Ranney, Lavallee, \& Wemigwans, 2012; Deloria Jr., 1973; Freeman \& Lee, 2007; Green, 2009; Little Bear, 2000; Nabigon \& Nabigon-Wenger, 2012). Culturally informed responses and culturally based programs to individual and social issues are having positive results in healing and wellness movements; that is a fact (Wesley-Esquimaux \& Smolewski, 2004). Like many Indigenous knowledge keepers, I too believe wholistic frameworks will create lenses to facilitate wholistic thinking in development, planning and action toward comprehensive responses for complex and multifaceted issues and problems. Medicine Wheel frameworks, the Oolichan fishing, whole petal flowers, whole trees, stitching and sewing and other countless examples can facilitate balance and considerations of all aspects within the spiritual, emotional, mental and physical elements; and all those elements in relationship with and to the whole environment, past, present and future (Graveline, 1998; Green, 2009; Hart, 2002; Jackson, Coleman, Strikes With A Gun \& Sweet Grass, 2015). Additionally, wholistic frameworks based on the hand drum and sacred circle teachings with all its' elemental directions have guided a lens for considerations and movement toward inclusion (Goudreau, Cote-Meek, Madill, \& Wilson, 2008; Hart, 1996, 2002; Nabigon, 2006).

Figure 1 presents an illustration of a wholistic framework drawn from the Four Directions of Medicine Wheel and Seven Sacred Teachings (Benton-Benai, 1988; Nabigon, 2006). This wholistic framework is comprised of four interconnected and interrelated directions: spirit and vision; emotional and relationship; mental and knowledge; and physical and presence. Social inclusion of Indigenous peoples ought to be wholistic in perspective, approach and application. I begin with spirit and move around the circle following the direction of the sun. All directions are interdependent and interconnected and create a whole. Each must be attended. Balance is achieved by being mindful of all directions together to create a wholistic and ethical approach. Further, each element in this framework is guided by the Seven Sacred Teachings ${ }^{5}$ of humility, love, truth, honesty, respect, wisdom and bravery.

\footnotetext{
${ }^{5}$ Also commonly known as Seven Grandfather teachings. See the Mishomis Book (Benton-Banai, 1988) to understand the traditional story (aadizookaan) where the Seven Grandfathers presented a little child with each principle now known as the Seven Grandfather teachings. In this article I prefer seven sacred teachings to not exclude the notion of grandmothers.
}

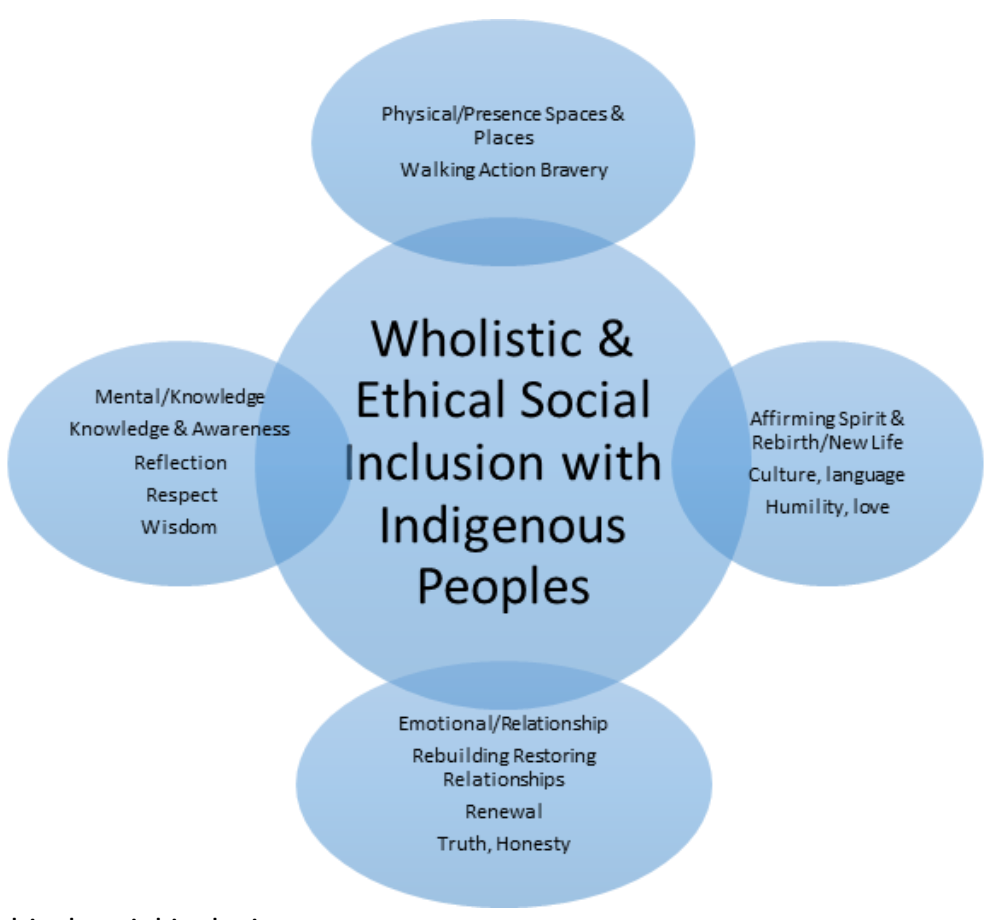

Figure 1. Wholistic and ethical social inclusion. 
These seven sacred teachings are guiding ethics governed by traditional knowledge intended to maintain and restore balance and harmony in Creation. The following illustration provides a visual of this culturallybased wholistic and a lens. This framework is a beginning and others will see what I have not and I invite others to build on this in a manner that promotes mino bimaadsiwin (a good life) for all. I begin with Spirit and move clockwise to include all directions; individually they are unbalanced, together they are whole.

\section{Spirit}

Spirit is ethically guided by the sacred teachings of humility and love. Inclusion has to be guided by unconditional love: love for the people, the project, humanity, healing and reconciliation. To know peace is to know the beauty and power of love. Humility is present when you know yourself as a sacred part of creation and that includes the spirit world. An Anishinaabe Elder, Pathfinder-bah, who I had worked with and learned from (now in the spirit world), shared that we are spiritual beings having a human experience. How humble is that! We are dependent on the air, water, sun and earth plus her inhabitants and plants for survival. Human beings are in humble position with respect to Creation. Indigenous teachings are simple and humble and walking with humility is a value enacted in learning to listen with presence and respect. New born babies encompass new life and renewal and are the closest to Spirit and they bring pure love into this earth lodge. I believe love is a spiritual virtue from Creator and because our Creator purely loves us unconditionally, we have been given everything we need to live a good life. Everything we need is in Creation unconditionally present. Life is offered and medicines to help us are offered in Creation. Attending to spirit is attending to that sacred relationship to Creator and Creation with love and humility. We are spiritual people whose worldview and philosophies are enacted acknowledging that we live in relationship with a Great Spirit, spirits in Creation and ancestral spirits. There is a fine line between this earthly realm and the spirit realm. Our ${ }^{6}$ ceremonies, feasts, dances, and gatherings all recognize and include Spirit. We are aware of the presence of spirit and nurturing our spiritual connection is one element of our whole human experience and an important determinant of social wellbeing. Further, it goes without saying that including Indigenous people in anything means attending to Spirit.

Colonial forces have attacked and attempted to annihilate our spirituality and connection to our Mother the Earth in an effort to sever this sacred connection in pursuit of land, mineral and resource exploitation. Be-

${ }^{6}$ When I say "our" my reference is intended to include Indigenous peoples' ceremonies. cause Indigenous spirituality and ways of life are intrinsically linked to Creation, the earth and all her resources, severing this connection was one key colonial agenda. However, words alone cannot describe the sacred and profoundly deep connection much like an umbilical cord between the people of Creation and our Mother the earth. The love is unconditional. She is the one who bestows life, food and medicine to Creation. She is the one who gives life to those who inhabit her. From Spirit, we consider affirming spirit along with a process of rebirth and new life. In any day we can try again and each new day is a new opportunity. Attending to the spirit is about affirming Indigenous peoples' spirit, culture, and language with humility and love toward rebirth and regeneration of social inclusion.

Some questions to guide in determining whether the spirit of Indigenous peoples is included are:

- Is spirit being attended to?

-What does cultural humility look like here?

- Are Indigenous peoples invited?

- Are spiritual leaders invited to guide spiritual inclusion?

- Are cultural protocols informing how people are invited and related to? If you don't know the cultural protocols identify who can help.

- Are Indigenous spiritual practices present and evident?

- Is there space for Indigenous peoples' medicine and ceremony?

- Who can provide leadership in creating space for spiritual practices?

- Are we including land based spiritual practices?

- Have we secured natural spaces for spirit and land based ceremony?

- What languages should be included?

- Others...?

Land and spirit are intrinsically connected. Being on the land is being in relationship with spirit. Indigenous people generally love being on the land. I encourage large land holders to share land space and places by invitation. Work with Indigenous peoples toward restoration of relationships with the original stewards of the land and Creation. On a purely idealistic level, I believe land must be returned to Indigenous peoples in order for the inclusion of Indigenous ceremonial practices to occur without permission or apology. Our ceremonies require a land base. The land is where the medicines, animals, helpers exist: this is where our life source is. We know the land will be our salvation for life and spaces and places are essential. Indigenous knowledge and learning doesn't happen in classrooms or inside buildings; it happens on the land and in Creation. Creation is comprised of our relatives and in order to enact spiritual practices, the Spirit of the land is central. 


\section{Emotional: Rebuilding Relationships}

The Emotional direction is guided by the sacred teachings of truth and honesty. Honesty is an important Indigenous ethic and when enacted brings strength to sharing ideas, experiences and knowledges. When people need strength and courage to speak their truth, they will often hold onto an eagle feather and it is believed that the spirit of that feather will bring the truth forward. Sometimes people speak their truth while holding onto the feather without having contemplated sharing it. Being truthful with self is the beginning and then being truthful and mindful with others fuels authentic relationship building. It takes courage to be truthful and honest about our place and challenges in any dynamics of oppression/oppressor, colonizer/colonized, settler/Indigenous, and decolonizing/ indigenizing. Through conversations genuine humanity can be restored. Truth and honesty require humility and love and all these values will teach us how to be real in healing and restoring wounded relationships within self and others.

Feeling included and invited are important emotional experiences on the pathway to social inclusion, restoration and reconciliation. Being invited is a positive experience and says 'we want you here'. We want you here indicates that your presence matters and what you have to offer will make a difference. Building relationship begins with an invitation. Through invitations and encounters possibilities exist to gain understanding, knowledge, connection, compassion and so much more. Relationships require contact and connections. With regard to relationship building, Leroy Little Bear (2000) again sums up how essential it is to meet, share, and exchange experiences, stories, truths and ideas. There are many truths and ideas of how, where, when, and what to do to bring social health and wellness to creation. He states:

"In a context of jagged worldviews, I cannot take for granted that you see and know the same things that I see and know. The only things I know for sure are the things I experience, see, feel, and so on. The rest of it is presumption and persuasion.... That is why we engage in conversation, so I can share my experiences with you and make you understand what I am feeling. When you respond, you are doing the same thing with me." (p. 85)

The above quote echoes a strong need for dialogue because we (Indigenous and non-Indigenous and everyone in between) have so much to sort out in restoring and rebuilding relationships based on respect. Relationship are key says Shawn Wilson when considering and engaging in ethical and inclusive Indigenous research (2008). Restoring healthy relationships was a primary recommendation for youth work in resiliency and recovery from substance abuse (Haring, Freeman, Guiffrida \& Dennis, 2012). Sharing, talking, healing, learning and teaching circles carry the means for creating respectful spaces for listening and sharing (Gaveline, 1998). Throughout this article, our diverse make-up has been established. Values of kindness in learning and sharing are leading pathways to building and restoring wounded relationships within ourselves and amongst each other. We have to tell our stories about who we are, where we come from and what all that means to us. We all could practice acceptance and respect for diversity in the truth that we all have diverse histories and social stories. We all have commonalities and bridge building is possible. Creating space to begin or to continue listening and learning is a start in any relationship. I believe that most people can attest to the fact that healthy relationships require time, space, energy and honesty. There are many other factors that contribute to relationship building; however, the main point here is that for inclusion to become an experience, relationship building needs to be attended to with truth, honesty and respect. What a respectful relationship to experience when we are accepted for who we are, not by how others think we should be. I would definitely want to nurture and engage in those kinds of relationships. That means, as Leroy Little Bear as stated, our conversations of learning and sharing need to be less about verifying our presumptions and assumptions and more about learning, acceptance and respect.

Some of the following questions may guide the lens of attending to relationship building with truth and honesty:

- How will we create an inclusive and relationship building process?

- Who will coordinate a planning session to begin?

- Are Indigenous people who are relevant to the topic invited?

- Who will you invite? Inviting people who have interests indicates an investment in a meaningful and purposeful process.

- Is there a space that generates respect in the sharing of ideas? Creating spaces that allow people space to share, engage $\&$ be on land is helpful.

- What mechanisms are in place to ensure Indigenous people are listened to?

- How will respect be enacted?

- What truths need to be shared?

- What Indigenous process can be integrated to foster respectful sharing and listening: relationship building? Ask about the circle process.

- What activities and events can be planned that build respectful and inclusive relationships with Indigenous peoples? 
- Other suggestions...?

Attending to relationships with truth and honesty is not only restorative; interwoven in these values are integrity and respect. Settler-Indigenous relations have been riddled with the presence of puzzled and jagged worldviews colliding crashing, clashing and smashing (Little Bear, 2000). Sorting out the puzzle is not easy, but in the spirit of renewal, truth telling and truth listening will foster the sorts of relationships that people want to be involved in. I think people are tired of contrived attempts (rightly so) and are thirsty for real conversations about real life experiences, issues, challenges, journeys toward truth building and truthful problem solving.

\section{Mental: Knowledge and Understanding}

The mental direction calls attention to knowledge building and critical reflection and are guided by the sacred teachings of respect and wisdom. Herb Nabigon (2006) explains respect as having the capacity to look twice at things. Herb, an Anishinaabe Elder, was one of my first cultural teachers many years ago. He taught me that by learning to look twice at what we are observing or thinking about, we learn about respect. We can learn to not react, but to become reflective and retrospective in thought. Showing respect is to take time to take a second look and let the first re-action go, to reflect and look again. What this means in acts of inclusion is to not make quick judgements at who belongs and who doesn't, but to reflect and invest in thoughtfulness before acting or reacting. Knowledge can emerge when time and space are created and from this knowledge, developments, planning and movements that are respectful can emerge. There is wisdom in Indigenous knowledge, traditions, ceremonies and teachings. As this article is promoting, show respect for Indigenous knowledge and wisdom through authentic inclusion. What I mean by authentic inclusion is inclusion that Indigenous people feel and experience as real, genuine and meaningful.

Readiness is always a factor that enables or disables any process from moving forward in a productive manner. Education and training become important to preparing and fostering a climate of readiness. For example, if a group wants to include Indigenous peoples in a movement, the group must understand that Indigenous peoples in Canada have both a rich cultural history and deep colonial history. Both of these histories are real and have significant implications for truth and reconciliation in Canada. Both of these histories have led to excluding or including. The rich cultural traditions of Indigenous peoples which this article promotes, will lead toward pathways that foster inclusion. Mechanisms of colonization, assimilation, annihilation and genocide have led to the exclusion of Indigenous peo- ples. The pathway is clear for those that are invested in working toward inclusion of Indigenous peoples.

When considering the mental or knowledge portal of a wholistic and ethical action toward social inclusion and Indigenous peoples, as I stated earlier, the importance of understanding who Indigenous peoples are in terms of our cultural histories, territories, languages and our colonial histories cannot be emphasized enough. For example, when considering Indigenous peoples' cultural histories and locations, Canada is a composite of diverse and vast Indigenous territories comprised of over six hundred First Nation communities on reserve; urban Indigenous communities and rural Indigenous communities (Dickason \& Newbigging, 2015). Research states that there are up to seventy Indigenous languages which are linguistically grouped into twelve groups (Official Languages and Bilinguialism Institute, n.d.). The geographical, land and territorial diversity of Indigenous peoples in Canada is large. Any individual or group wanting to include and engage with Indigenous peoples needs to learn about, understand and educate themself on who they are engaging with, thus avoiding a pan-Indian response. There are similarities and commonalities, the challenge is to be able to discern what these are.

Similar to other colonized countries, Canada has a history of cultural genocide against Indigenous peoples (TRC, 2015). The Federal Government funded Church run schools to assimilate Aboriginal children with an attempt to kill the culture in them. This resulted in an unforgettable era and legacy of residential schooling which left thousands of Indigenous children and following generations with deep-seeded trauma and wounds steeped in the spiritual, emotional, mental and physical abuses the children and their families incurred. This history was largely ignored and in 2007 the Canadian Federal Court Approved an Indian Residential Schools Settlement Agreement in Canada which led the pathway to a process called the Indian Residential School Truth and Reconciliation Commission ${ }^{7}$ from 2010 to 2015. From the TRC website I include the following:

\section{What is the TRC? \\ The TRC is a component of the Indian Residential Schools Settlement Agreement. \\ Its mandate is to inform all Canadians about what happened in Indian Residential Schools (IRS). The Commission will document the truth of survivors, families, communities and anyone personally af- fected by the IRS experience. \\ This includes First Nations, Inuit and Métis former Indian Residential School students, their families, communities, the Churches, former school employ- ees, Government and other Canadians.}

\footnotetext{
${ }^{7}$ Go to www.trc.ca for more information, resources and to see the 94 recommendations in the final report.
} 
The Commission has a five-year mandate and is supported by a TRC Secretariat, which is a federal government department.

\section{What does the TRC hope to achieve?}

The TRC hopes to guide and inspire Aboriginal peoples and Canadians in a process of reconciliation and renewed relationships that are based on mutual understanding and respect. (TRC, 2015)

In June, 2015, my partner and I attended the final events of the TRC in Ottawa, Ontario where Justice Murray Sinclair presented the final summary and subsequent 94 recommendation report compiled from 5 years of statement gathering and research. The recommendations directly address issues of inclusion in all areas of child welfare, health, justice, education, language and culture, youth, churches, museums, buried children and national monuments, a national centre for reconciliation, the Royal Proclamation and a covenant for reconciliation, and United Nations declaration for Indigenous peoples. The recommendations themselves indicate that inclusion across the board is necessary. A call for action is the foundation of the recommendations-calls for action by the Federal Government in all areas of funding, legislation, institutional development, education and policy to redress and begin to move forward toward reconciliation.

At the closing event on May 31, 2015, my husband and I walked alongside seven thousand other people through the streets of Ottawa with a call to action to the Government and many other witnesses to support the truths of Indian residential school survivors and their families. On that particular day, thousands of people united and there was a felt inclusion for the support and intentions of the TRC. The march, like many, created a visible presence of support with a hope that the millions of witnesses watching from the sidelines of the streets, media and social media would care and step forward to move the Federal Government to respond to this call to action. Later, I made a statement on the impact of the Indian residential school on my uncles, aunts, grandparents and parents and the intergenerational impacts on myself, siblings, cousins and future children. During this process I felt included and listened to. I wanted to name my relatives whose lives have been negatively impacted by the IRS. I wanted to acknowledge and have recorded the loss of family ties, communities, cultural identity, language, health, wellness, self-worth coupled with the occurrences of spiritual, emotional, mental, physical and sexual abuse that were rampant throughout these schools. I wanted their names to be recorded and remembered and like many others, I wanted their stories to be acknowledged and included.

Some questions to consider in wholistic and ethical social inclusion from the mental/knowledge direction are:
- Who will assess capacity and readiness and determine education and training needed? How will this be done?

- Is there education being provided on the truth and history of Canada and Indigenous people?

- Is education development and Indigenous illiteracy being addressed? Are resources and material available and facilitated?

-What education and training preparations need to developed and delivered?

- How will education foster decolonization while restoring Indigenous peoples' culture, traditions, language and land?

-Who are the local Indigenous peoples, their languages and land base?

-Where learning tools, resources, teachers and educators are available?

- What Indigenous languages need to be included and resourced?

-What existing practices/research to build on?

- Any other thoughts...?

Understanding, knowledge, respect, wisdom and truth telling culminate and enhance the possibility that inclusion from a place of respect is possible. In any action of inclusion one needs to know intelligently that other peoples' knowledge is valid and deserving of space. Indigenous knowledge will guide the methodologies from which action can emerge. From this place of respect, knowing and being, inclusion becomes an experience felt by contrast with rhetoric espoused.

\section{Physical: Places and Presence}

The physical direction calls attention to presence, space and place and are guided by the sacred teaching of bravery. To physically walk with all these seven sacred teachings and to carry them in your whole being is to walk in bravery. To carry truth and honesty forward takes bravery. Bravery requires humility in being truthful especially when making amends is the action. Humility, love, truth, honesty, respect and wisdom are all related to being brave in our thoughts and actions. Standing up for inclusion takes bravery. Being the only one to see who is missing and speaking up takes bravery. Despite everything, Indigenous peoples know we belong and we know through our creation stories that we have a purpose in Creation. Presence and places are important considerations. Indigenous peoples want to see other Indigenous peoples' presence in places that are welcoming, warm and respectful.

Through the many barriers in history and moving forward, Indigenous peoples have made strides and set strong examples for the rest of Canada and the world. We have seen resistance movements through Oka, Idle No More, Indigenous women movements, Indigenous 
youth-lead walks for better schools and education, women water walkers for the water, and growing Aboriginal rights movements and they are impacting public and social policy. Today many First Nations and Indigenous peoples are more visible and are playing more significant roles in fostering change and leading movements that may well help restore humanity to people and restore respect for our life source, the earth. Indigenous women are a growing voice and presence is consciousness raising and have been leaders in activism and social movements. The Idle No More ${ }^{8}$ movement became a national mobilizer for peoples' attention to join a peaceful revolution to stand up for rights, land, water and living conditions in Canada among Indigenous peoples. The presence and evidence of Indigenous peoples in social movements and walks of bravery and courage, fights for change, and challenges to injustice is indeed growing.

Internally in Indigenous communities we are building culturally-based frameworks for the social inclusion of all members in our communities. These models exist within Indigenous organizations such as healing and wellness centres and are created from Indigenous knowledge, traditions and protocols. For example, in Ontario and across Canada, Native child welfare developments are growing and developing governance models from their own wholistic knowledge bundles from their Nations territories and traditional knowledge. One local example in southwestern Ontario is Mnnaasged $^{9}$ where wholistic approaches to healing and restoring Indigenous knowledge and values at the centre of agency development. Mnaasged's Executive Director, Carrie Tabobondung (an Anishinaabekwe from Wasauksing First Nation, Ontario), states that she has seen "so many incredible changes in child welfare on the outside but mostly we've grown as an organization together on the inside" (Tabobondung, 2015). Culturally-infused models governed by the seven sacred principles create a consciousness of mutual respect which in turns fosters inclusion of members of all age groups and members from various belief systems. The value of inclusion is not new in Indigenous knowledge systems. Today, it is more of a matter of re-building and restoring our values into how we build social systems. I believe in our Creation stories which tell us that we, Indigenous people, belong here and without us Creation would be incomplete. Hope, faith, truth and courage carry me forward to continue in areas where I strive to open up doors and windows and to remove obstacles toward inclusion and authentic social change.

A strong presence and visibility is a part of inclusion. We must see that we are being included. When one sits at a table to discuss anything Indigenous, a

\footnotetext{
8 Website: www.idlenomore.ca

${ }^{9}$ Go to www.mnaasged.ca for more information on this Indigenous child welfare organization.
}

glance around the room ought to reveal other Indigenous people, stake holders, Elders, youth, women, men, leaders, and grandmothers/fathers present. Who this is about ought to be present. The presence of people and the presence of their voice is an indication that inclusion is authentic. The TRC walk I referred to earlier was a powerful experience of presence. Presence of the people, presence of the testimonies, stories and relatives, presence of memory and telling, and presence of process counters invisibility and exclusivity of truths. Reconciliation requires truth of sharing, truth of accounts, truth of accountability and truth of presence. Reconciliation is only possible when the truth is shared and accepted as the truth. People will march and people will walk. When people collectively walk together, a power of presence and undeniable truths are visible. The excluded seek inclusion by creating visibility in marching, chanting, going hungry and rallying at closed gates wanting voices to be heard and included in policy and funding. Bravery and courage are teachings that carry acts of dissention toward inclusion.

In considering the physical direction issue surrounding space and place warrant attention. Here are a few questions to guide inclusion of presence which is guided by bravery and courage:

-Whose Indigenous territory, land and place are you on?

-Whose traditional/ancestral territory \& Nation needs to be acknowledged?

- Is it reasonable to consider meeting in Indigenous spaces?

- Is meeting in Indigenous organizations or communities a possibility?

-What are the human resources that are accessible to ensure inclusion with Indigenous peoples is enacted?

- Hire people to research and explore Indigenous models and examples: research best practices and provide examples.

- What funding resources are available to support inclusion efforts?

-What physical resources are available?

- Is anything missing, forgotten or overlooked?

- Any other ideas...?

- So what do you think? As an Indigenous person, asking and inviting people to share their thoughts is an inclusive basic principle.

As a follow up note to the collective lists and guides to consider inclusion with Indigenous peoples, I remind the reader that these are guides. I'm sure with ongoing dialogue, there is more to consider and more possibilities to emerge. My hope is that the lists in each of the elemental arenas will usher in thoughts and ideas and foster a wholistic perspective. The goal after all is 
wholistic and ethical actions for social inclusion with Indigenous peoples.

\section{Some Final Thoughts}

Social inclusion with Indigenous peoples, or any diverse group for that matter, is challenging-don't get me wrong. It's a process and with each effort and attempt, as we learn and try again, a shift occurs and growth emerges. I presented many layers of skepticism, hope, spirit, heart, mind and presence to foster considerations toward a wholistic direction of social inclusion. These were further supported by the ethical guidance of the Seven Sacred Teachings. The Anishinaabe creation story (Benton-Benai, 1988) affirms that Creation would be incomplete without Indigenous peoples. Today I know I belong. I know I am not alone and I want to include and honor all of my children, family, teachers, Indigenous scholars, critical thinkers, fellow travelers and truth seekers. We all are working to heal, restore, recover and reclaim our place in society along with the restoration and resurgence of Indigenous knowledge in strategies and approaches is growing and being asserted (Hart, 2014; Simpson, 2011). We are all in this together. The reality for Indigenous peoples in Canada and North America is that we are diversely blended in our identities, social and political locations. Arriving at an authentically inclusive wholistic and ethical place and space of social inclusion is a challenging task. Years ago, while on my own search and re-search (Absolon, 2011) to understand the myriad of confusion, I came across Leroy Little Bear's (2000) article on Jagged Worldviews Colliding and have referenced his insights in my work. In this article, his wisdom continues to ring true as he sums up the ex/inclusion collision nicely in the following:

"Colonization created a fragmentary worldview among Aboriginal peoples. By force, terror and education policy, it attempted to destroy the Aboriginal worldview-but it failed. Instead, colonization left a heritage of jagged worldviews among Indigenous peoples. No one has a pure worldview that is 100 percent Indigenous or Eurocentric; rather, everyone has an integrated mind, a fluxing and ambidextrous consciousness and back again. It is this clash of worldviews that is at the heart of many current difficulties with effective means of social control in postcolonial North America. It is also this class that suppresses diversity in choices and denies Aboriginal people harmony in their daily lives." (p. 85)

Because Leroy Little Bear articulates the anguish of many of us, I tend to refer back to his wise words in describing the impacts and challenges today. Colonization has impacted all of us profoundly and we all have a role to play and work to do to restore inclusion and humanity to the world without harm. Understanding how we've been impacted and finding our truths, healing and humanity in the process is a life journey. The four directional circle journey is only one example of how my Anishinaabe culture and many other Indigenous knowledges informs how we can approach and consider inclusion. There are many other cultural frameworks informed by each Nations Indigenous knowledge and context. I encourage all Indigenous peoples to build and restore our place in society and Creation from the knowledges steeped in our cultures.

Patterns, puzzles and layers are what characterize who we are today and what work lays ahead in making meaning from it all. They are beautiful and complex. Efforts for social inclusion may be met with layers of suspicion, mistrust, self-doubt, anger, hurt, fear and worry. I believe and have hope that when action is guided by authentic knowledge along with principles of love, humility, truth, honesty, respect, bravery and wisdom these layers, wounds and barriers will be replaced with actions that move one's spirit, heart, mind and body into a place of humility, love, truth, honesty, respect, wisdom and bravery. The circle is a powerful teaching. These seven sacred principles are strong values gifted through powerful traditional ceremonies. They are medicine for mino bimaadsiwin, a good way of life. When we strive for that wholistic and balanced good life, goals of social inclusion are possible. Miigwech!

\section{Acknowledgments}

I wish to acknowledge all the teachers and mentors' whose teachings and examples make this world richer and more inclusive for all peoples. I acknowledge all those who do their best to walk, research and write with love, humility, truth, honesty, bravery, respect and wisdom toward addressing injustices for inclusion, healing and restoration. I acknowledge my colleagues, my family and partner for all their support. To the editors of this journal, I am grateful for your kind support. Miigwech to all of Creation and all my relations!

\section{Conflict of Interests}

The author declares no conflict of interests.

\section{References}

Aboriginal Field of Study. (2015). Lyle S. Hallman Faculty of Social Work. MSW Aboriginal field of study (Program Pamphlet). Kitchener: Wilfrid Laurier University. Retrieved from www.wlu.ca

Absolon, K. (2010). Indigenous wholistic theory: A knowledge set for practice. First Peoples Child and Family Review, 5(2), 74-87.

Absolon, K. (2011). Kaandossiwin: How we come to know. Winnipeg: Fernwood Publishing. 
Absolon, K. (2009). Navigating the landscape of practice: Dbaagmowin of a helper. In R. Sinclair, M. Hart, \& G. Bruyere (Eds.), Wicihitowin Aboriginal social work in Canada (pp. 172-199). Winnipeg: Fernwood Publishing.

Benton-Banai, E. (1988). The Mishomis book. Hayward, WI: Indian Country Communications Inc.

Cajete, G. (1994). Look to the mountain: An ecology of Indigenous education. Durango, CO: Kivaki Press.

Cote-Meek, S., Dokis-Ranney, K., Lavallee, L., \& Wemigwans, D. (2012). Building leadership capacity amongst young Anishinaabe-kwe through culturallybased activities and creative arts. Native Social Work Journal, 8, 75-90.

Deloria, V, Jr. (1973). God is red. New York: Dell.

Dickason, O., \& Newbigging, W. (2015). A concise history of Canada's First Nations ( $3^{\text {rd }}$ ed.). Toronto: Oxford University Press.

Dion, S. (2009). Braiding histories. Learning from Aboriginal Peoples' experiences and perspectives. Vancouver: University of British Columbia Press.

Dumbrill, G., \& Green, J. (2008). Indigenous knowledge in the social work academy. Social Work Education, 27(5), 489-503.

Dumont, J. (1976). Journey to daylight: Through Ojibway eyes. Laurentian University Review, 8 (2), 31-43.

Freeman, B., \& Lee, B. (2007). Towards an Aboriginal model of community healing. Native Social Work Journal, 6, 97-120.

Freire, P. (1996). Pedagogy of the oppressed. New York: Continuum.

Goudreau, G., Cote-Meek, S., Madill, H., \& Wilson, S. (2008). Hand drumming: Health-promoting experiences of Aboriginal women from a Northern Ontario urban community. Journal of Aboriginal Health, 4(1), 72-83.

Graveline, J. F. (1998). Circle works: Transforming Eurocentric consciousness. Halifax, NS: Fernwood Publishing.

Graveline, J. F. (2010). Oh Canada. Our Canada. One of four against. Critical Social Work, 11(1), 81-88.

Gray, M., Coates, J., \& Yellow Bird, M. (Eds.). (2008). Indigenous social work around the world. Towards culturally relevant education and practice. Burlington: Ashgate Publishing.

Green, J. (2009). Gyawaaglaab (Helping one another): Approaches to best practices through teachings of Oolichan fishing. In R. Sinclair, M. Hart, \& G. Bruyere (Eds.), Wicihitowin Aboriginal social work in Canada (pp. 222-233). Winnipeg: Fernwood Publishing.

Haring, R. C., Freeman, B., Guiffrida, A. L., \& Dennis, M. L. (2012). Relationship building for a healthy future: Indigenous youth pathways for resiliency and recovery. Journal of Indigenous Social Development, 1(1), 1-17.

Hart, M. A. (1996). Sharing circles: Utilizing traditional practice methods for teaching, helping and support- ing. In S. O'Meara \& D. A. West (Eds.), From our eyes: Learning from Indigenous peoples (pp. 59-72). Toronto: Garamond Press.

Hart, M. (2002). Seeking Mino-Pimatisiwin. An Aboriginal approach to helping. Winnipeg: Fernwood Publishing.

Hart, M. (2014). Introduction. Indigenous knowledges: Resurgence, implementation, and collaboration in social work. Journal of Indigenous Social Development, 3(2), 1-4.

Jackson, E. L., Coleman, J., Strikes With A Gun, G., \& Sweet Grass, D. (2015). Treading, stitching, and storytelling: Using CBPR and Blackfoot knowledge and cultural practices to improve domestic violence for Indigenous women. Journal of Indigenous Social Development, 4(1), 1-27.

Linklater, R. (2014). Decolonizing trauma work. Indigenous stories and strategies. Winnipeg: Fernwood Publishing.

Little Bear, L. (2000). Jagged worldviews colliding. In M. Battiste (Ed.), Reclaiming Indigenous voice and vision (pp. 77-85). Vancouver: UBS Press.

Little Bear, L. (2012). Traditional knowledge and humanities: A perspective by a Blackfoot. Journal of Chinese Philosophy, 31(4), 518-527.

Nabigon, H. (2006). The Hollow Tree. Fighting addiction with traditional Native healing. Montreal and Kingston: McGill-Queen's University Press.

Nabigon, H., \& Wenger-Nabigon, A. (2012). "Wise Practices": Integrating traditional teachings with mainstream treatment approaches. Native Social Work Journal, 8, 43-55.

Official Languages and Bilinguialism Institute. (n.d.). Site for language management in Canada. Retrieved from https://sImc.uottawa.ca/?q=native_peoples_languag es

Pinderhuges, E. (1998). Understanding race, ethnicity and power. The key to efficacy in clinical practice. New York: Free Press.

Simpson, L. (2011). Dancing on our turtle's back. Stories of nishnaabeg re-creation, resurgence and a new emergence. Winnipeg: Arbeiter Ring Publishing.

Tabobondung, C. (2015). Message from Executive Director. Retrieved from www.mnaasged.ca

Truth and Reconciliation Commission. (2015). Retrieved from http://www.trc.ca/websites/trcinstitution/inde x.php?p=3

Twigg, R. C., \& Hengen, T. (2009). Going back to the roots: Using the medicine wheel in the healing process. First Peoples Child and Family Review, 4(1), 1019.

Verniest, L. (2006). Alleying with the medicine wheel: Social work practice with Aboriginal peoples. Critical Social Work, 7(1). Retrieved from http://www. uwindsor.ca/criticalsocialwork

Wesley-Esquimaux, C. C., \& Smolewski, M. (2004). Historic trauma and Aboriginal healing: The Aboriginal 
Healing Foundation research series. Ottawa, ON: The Aboriginal Healing Foundation.
Wilson, S. (2008). Research as ceremony. Halifax: Fernwood Publishing.

\section{About the Author}

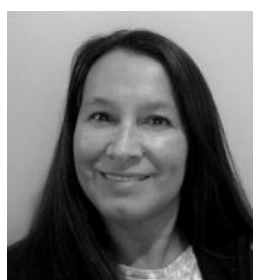

\section{Dr. Kathleen E. Absolon}

Dr. Kathleen Absolon is member of Flying Post First Nation. Her blend inlcudes both Anishinaabe and British ancestry. She is an Associate Dean and Associate Professor in the Aboriginal Field of Study, Faculty of Social Work, Wilfrid Laurier University. She is an Indigenous practitioner, educator and researcher. She published Kaandossiwin: How We Come to Know (2011) among other works related to wholistic knowledges, community practice and Indigenous methodologies. 